\title{
Letters to the Editor Anthology: An e-Supplement Resource
}

\author{
Mark Roh ${ }^{1}$, Deborah Whippen ${ }^{2}$, and Charles Balch ${ }^{3}$ \\ ${ }^{1}$ UF Health Cancer Center Orlando, Orlando, FL; ${ }^{2}$ Editorial Office, North Fort Myers, FL; ${ }^{3}$ University of Texas MD \\ Anderson Cancer Center, Houston, TX
}

Annals of Surgical Oncology publishes here for the first time an anthology of Letters to the Editor and additional correspondence from Annals authors and readers. These letters serve as an archive of communications between Annals authors and the readers of our journal. We offer in one collection Letters to the Editor that were received, approved, and previously posted to the Society of Surgical Oncology website. The journal's annual electronic supplement provides a forum in which this multi-year collection can be provided in one anthology for convenient access.

This repository of dialog about journal content includes updates and commentary regarding developments in our field related to the practice of surgical oncology. As readers will discover, and as has been noted elsewhere, Letters to the Editor often give additional insights, provide corrections, summarize alternate theories, and point to areas where reported evidence may be strengthened or challenged. ${ }^{1-3}$ Letter to the Editor communications also provide a forum in which younger colleagues can engage in scientific discourse with authors of full-length research articles to the benefit of readers. ${ }^{1}$

We trust this additional resource will strengthen the impact of research published in Annals of Surgical Oncology for the betterment of surgical oncology patients worldwide.

\section{REFERENCES}

1. Tierney E, O'Rourke C, Fenton JE. What is the role of "the Letter to the Editor"? Eur Arch Otorhinolaryngol. 2015;272:2089-93.

2. Falavarjani KG, Kashkouli MB, Chams H. Letter to Editor, a scientific forum for discussion. J Curr Ophthalmol. 2016;28(1):1-2.

3. Brown CJ. Unvarnished viewpoints and scientific scrutiny. Letter to the editor provide a forum for readers and help make a journal accountable to the medical community. CMAJ. 1997;157(6):792-4.

(C) Society of Surgical Oncology 2017

First Received: 31 October 2017;

Published Online: 22 November 2017

C. Balch

e-mail: balch@asoeditorial.org 